DOI 10.37882/2223-2982.2020.11.36

\title{
COВРЕМЕННЫЕ ТЕНДЕНЦИИ РАЗВИТИЯ ЯЗЫКОВОЙ ИГРЫ В АНГЛИЙСКОМ ЯЗЫКЕ (ПО МАТЕРИАЛАМ АНГЛОЯЗЫЧНОЙ ПРЕССЫ)
}

\section{MODERN TRENDS IN THE DEVELOPMENT OF A LANGUAGE GAME IN ENGLISH (ACCORDING TO THE ENGLISH-LANGUAGE PRESS)}

\section{S. Feopentova}

Summary: The article presents the results of the study of the language layer of the English-language press for the actualization of the language game from the point of view of its communicative task. The purpose of the article is to establish modern trends in the creation and use of such technique as a language game in the English-language press. Tasks: to establish a working definition of the concept of a language game; systematize the types of language games; to highlight the models of the language game on the basis of practical material; to define the communicative task of the language game in the English-language press. Hypothesis: the events of the last year (the coronavirus pandemic and related circumstances), being a significant factor that influenced the activities of states in general, and the lives of individuals, in particular, having received large-scale coverage in the media, provoked an active discussion in the press, including in English. It seems that such a colossal event requires journalists to use special methods of linguistic influence on the audience, one of which is a language game. Methods: method of systematization and generalization, sampling of examples, linguo-stylistic analysis. The material of the research was newspaper articles headings containing the language game. The headlines selected for the study were obtained by the method of continuous sampling from electronic versions of English-language (The Independent, The Telegraph, The Guardian, The Times, The Sun, The American (onservative) newspapers and magazines of various thematic focus for 2019-2020. Results: the article presents the results of the analysis of the use of the language game in the Englishlanguage press in terms of the implementation of the communicative task of journalists, in particular in the aspect of manipulative influence and imparting imagery to the presented material. Language game is one of the most widespread techniques used in journalism. The popularity of this technique in headlines is due to its formal and evaluative nature.

Keywords: language game, style-forming technique, word formation, word-formation activity, coronavirus pandemic, manipulative influence, English-language press.

\author{
Феопентова Светлана Владимировна \\ старший преподаватель, Российский государственный \\ аграрный университет-МСХА имени К.А. Тимирязева \\ sfeopentova@mail.ru
}

Аннотация: В статье представлены результаты исследования языкового пласта англоязычной прессы на предмет актуализации языковой игры с точки зрения коммуникативной задачи. Целью статьи является установление современных тенденций в создании и использовании такого приема, как языковая игра в англоязычной прессе. Задачи: установить рабочую дефиницию понятия языковая игра; систематизировать виды языковой игры; на практическом материале выделить модели языковой игры; определить коммуникативную задачу языковой игры в англоязычной прессе. Гunoтеза: события, происходящие во всем мире (пандемия коронавируса и связанные с ней обстоятельства), являясь существенным фактором, повлиявшим на деятельность государств, в общем, и жизнь отдельных людей, в частности, получив масштабное отражение в СМИ, спровоцировала активное обсуждение в прессе, в том числе в англоязычной. Представляется, что столь колоссальное событие требует от журналистов особых способов языкового воздействия на аудиторию, одним из которых является языковая игра. Методы: метод систематизации и обобщения, сплошной выборки примеров, лингвостилистического анализа. Материалом исследования послужили заголовки, содержащие языковую игру. Отобранные для исследования заголовки были получены методом сплошной выборки из электронных версий англоязычных (The Independent, The Telegraph, The Guardian, The Times, The Sun, The American Conservative) газет и журналов различной тематической направленности за 2019-2020 годы. Результаты: в статье представлены результаты анализа использования языковой игры в англоязычной прессе с точки зрения реализации коммуникативной задачи журналиста, в частности, в аспекте манипулятивного воздействия и придания образности излагаемому материалу. Языковая игра является одним из наиболее распространенных приемов, использующихся в публицистике. Популярность данного приема в заголовках обусловлена их формальной и оценочной природой.

Ключевые слова: языковая игра, стилеобразующий прием, словообразование, словообразовательная активность, пандемия коронавируса, манипулятивное воздействие, англоязычная пресса.

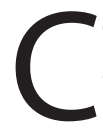

оциальные и политические изменения, смена формата подачи информации в публицистике привели к переменам, которые отразились не только в тематической направленности изданий, но и в языке средств массовой информации. Так, одной из тенденций в текстах современных СМИ является демократизация языка, что включает в себя нарушение языковых норм для достижения коммуникативных целей автора. Одним из средств, которое позволяет успешно достичь этих целей, является языковая игра (далее - ЯИ). 
Языковая игра как стилистический прием и средство эмоционального воздействия на читателя является объектом пристального внимания современных отечественных и зарубежных лингвистов (В.В. Васюк и О.В. Егорова [1], Е.А. Власова и К.А. Испаева [3], Е.А. Неревяткина и Н.А. Белова [4], М. Хорубет [10], Р. Дебора и Дж. Абел [9] и др.). Такой научных интерес обусловлен тем фактом, что языковая игра обладает колоссальным потенциалом оказания образного, манипулятивного потенциала на читателей. Исследователи медиа сходятся во мнении, что в современном обществе ведётся непрерывная информационная война, поэтому создатели новостей делают все возможное, чтобы сформировать в обществе нужное мнение. Журналисты находятся в постоянном поиске новых способов привлечь внимание читателей, акцентируя внимание именно на нужных аспектах. С целью создать яркий, образный материал часто используется прием игры слов.

ЯИ окружает нас везде - художественная литература, тексты публицистического жанра, реклама, разговорная речь. Несмотря на широкое использование данного приема в различных контекстах, до сих пор нет единого подхода к определению границ языковой игры. Условно все подходы к определению языковой игры можно разделить на широкий и узкий.

Широкий подход связан с философским пониманием языковой игры как одного из видов языковой деятельности человека. Основоположником такого подхода является австрийский философ Л. Витгенштейн, который и ввел термин «языковая игра». Термин "Language game" произошел от немецкого "Sprachspiel" и используется для описания языка как системы конвенциональных правил, в которых участвует говорящий. Философ определяет это языковое явление как «целое, состоящее из языка и тех видов деятельности, с которыми он сплетен» [2, c. 82].

Более узкое понимание ЯИ нашло отражение в работе В.3. Санникова «Русский язык в зеркале языковой игры», в которой автор рассуждает о соотношении таких понятий, как «речевая игра» и «языковая игра» и утверждает, что языковая игра действительно функционирует в речи, а эффект зависит от особенностей собеседника и ситуации, то есть от экстралингвистических факторов, термин «языковая игра» предпочтительнее, так как игра возможна только в том случае, если говорящий знаком с языковыми нормами, способами их употребления и интерпретации [6, с. 15].

Как отмечает британский филолог Д. Кристал, авторы вынуждены создавать интригующий, но в то же время наиболее полно передающий суть статьи заголовок в ограниченном пространстве газеты [8, р. 174]. Языковая игра в газетном тексте способствует наиболее точной передаче оценки описываемых в статье событиях, а также вызывает чувство интеллектуального удовлетворения при удачной расшифровке отсылок в заголовке, что соответствует коммуникативным задачам текстов публицистического жанра [4, с. 40]. Тем не менее, такая игра должна быть прозрачной, а также должны учитываться культурологические знания аудитории, иначе высок риск «отпугнуть» читателя сложностью [4].

Анализ теоретического материала по проблеме классификации средств создания ЯИ показал, что единой классификации не существует. В связи с этим представляется логичным дать краткую характеристику средств на каждом языковом уровне и составить классификацию на основе отобранного для анализа языкового материала.

На фонографическом уровне рассматривается языковая игра с фонетическим и графическим языковыми уровнями, на которых соблюдаются наиболее строгие нормы, их нарушение может привести к неправильной интерпретации значения языковой единицы. Фонетическая игра включает в себя игры со звуковым сходством лексических единиц или изменением их звуковой формы, а также общей звуковой организации текста. Графическая же игра представляет собой не только обыгрывание графического сходства лексических единиц, например, омографов, но и игры со шрифтом, цветом, знаками пунктуации, а также знаками других семиотических систем, что делает использование такого вида игры в газетном материале более обоснованным, нежели фонетического.

Основные средства создания языковой игры на фонетическом уровне - частичное совпадение звуков, аллитерация, ассонанс, обыгрывание омоформ, паронимическое сближение слов, перестановка звуков, звукоподражание, например:

Broken Hart: Joe vows to fight for Manchester City spot (The Independent, 2019).

В данном примере автор обыгрывает омофонию фамилии голкипера Joe Hart [ha:t] и существительного heart [ha:t]; автор сообщает и о предмете статьи, а именно о голкипере, а также о его подавленном состоянии из-за того, что он был вынужден остаться на скамейке запасных во время матча. В данном случае актуализируется смыслообразующая функция.

Pretty fly for a white guy: insect on Mike Pence's head upstages vice-president (The Guardian, 2020).

Данный заголовок сразу привлечет внимание тех, кто пристально следит за избирательной кампанией в США. Факт того, что муха [a fly], которая находилась на голове Вице-президента во время дебатов, был обыгран во мно- 
гих новостных выпусках [fly-guy -[flai-gai]]. В ряде новостей была отмечена необычная краснота глаз Вице-президента, что также нашло отражение на фонетическом уровне [flai-gai-ai].

Средства языковой игры на графическом уровне капитализация, псевдочленение узуального слова, полупунктуализация, голофразис, использование других семиотических систем, реверсивные акронимы, анаграммы, парентезис.

Языковая игра на лексическо-фразеологическом уровне представлена широким спектром средств: словообразовательной контаминацией, обыгрыванием значений многозначных слов и омонимов, псевдоантонимов и псевдосинонимов, фразеологизмов, а также художественными тропами, в основном, метафорами, например:

KNIGHTMARE: Rapper Ceon Broughton, aka CEONRPG, dresses as a knight in bizarre music video directed by brother of the girlfriend he left to die at Bestival (The Sun, 2019).

Заголовок газетной статьи начинается со словообразования knigntmare (knight + nightmare), с помощью которого автор дает негативную оценку действиям рэпера, который снялся в скандальном клипе в рыцарских доспехах. Игра дополняется омофонией слов night и knight, что делает ассоциацию с ночным кошмаром явной и не вызывает затруднений при расшифровке игры.

По этому же принципу образовано следующее окказиональное слово:

The 10 kinds of Covidiot you'll see in the park this weekend (The Telegraph, 2020)

Неологизм covidiot образован путем стяжения двух основ - covid и idiot, с точки зрения семантического значения слово используется для номинации лиц, которые полностью пренебрегают данными официальными лицами рекомендациями по предотвращению распространения коронавирусной инфекции, и подвергают тем самым себя и свое ближайшее окружение риску заражения, либо же, напротив, для обозначения тех людей, которые в утрированной форме следуют всем мерам предосторожности. Обладая саркастическим потенциалом, прием языковой игра в данном случае играет пропагандирующую роль, которая состоит в том, что читатель, ознакомившись с данным новостным материалом, не захочет уподобляться действиям тех, кого называют covidiot и будет придерживаться правил безопасности, установленных во время пандемии коронавируса.

В языковую игру могут быть вовлечены также и прецедентные феномены, например:

Trump turned it into Meet the Press by way of The Jerry Springer Show (The American Conservative, 2020).
В статье, опубликованной на следующий день после первых дебатов Д. Трамп и Дж. Байденом (30 сентября 2020 г), автор использует ссылку на «Шоу Джерри Спрингера»-телевизионную передачу в формате токшоу, которая известна в англоязычном обществе как скандальная, грубая и ориентированная на насилие. Используя такой прием, автор статьи, не выражая своего откровенного мнения по поводу поведения действующего президента США во время дебатов, тем не менее, дает аудитории понять ту ситуацию, которая сложилась на мероприятии.

Нельзя забывать, что одним из сильнейших инструментов эмоционального воздействия на читателей является юмор. Журналисты стараются использовать такое лингвистическое средство как ЯИ при подготовке новостного материала.

Привлекает внимание ряд шутливых и насмешливых слов:

The Covid Honours: Order of Superspreader

C.B.E. - Covid Bungler Extraordinary

Test\&Trace Star (The Times, 2020)

Читатель, возможно, сможет ассоциировать себя с одной из групп, в зависимости от своего поведения во время распространения инфекции. Однако ЯИ довольно трудно расшифровать тем, кто не является носителем языка. Но иногда даже и они, не обладая определенными социальными, культурными и лингвистическими знаниями, не смогут полностью понять юмор, используемый в игре слов. Так как языковая игра - это намеренное нарушение языковых правил, довольно трудно понять ее, не зная этих самых правил.

Positive result. This means that Donald Trump must NOT, under any circumstances, leave the White House (The Telegraph, October 2020)

Данный заголовок сопровождает рисунок, на котором изображен второй кандидат на пост президента США. На лице Д. Байдена- медицинская маска, указательный палец правой руки направлен в сторону яркой надписи " Positive result" («Положительный результат»). Читатели легко соотнесут результат положительного теста на Covid-19, при котором заразившийся должен находится в изоляции, и возможном прохождением президента Трампа на второй президентский срок.

Анализ показал, что наиболее часто языковую игру в англоязычной прессе можно встретить в заголовках. Вопервых, это связано с тем, что заголовок - это то, на что читатель первым делом обращает внимание при выборе статьи для прочтения. Заголовок находится в одной из сильных позиций текста, вследствие чего является базой для эмоционального настроя читателя. Во-вторых, 
это связано с многофункциональностью самой языковой игры, которая помогает усилить основные функции заголовка, среди которых наиболее важными считаются рекламная и воздействующая.

\section{ЛИТЕРАТУРА}

1. Васюк В.В., Егорова 0.В. Особенности перевода игры слов (на материале заголовков современной англоязычной прессы) // Актуальные проблемы востоковедения. - Хабаровск: Тихоокеанский государственный университет, 2020. - С. 326-330.

2. Витгенштейн ЛЙ. Философские исследования. - М.: Философия-Neoclassik, 2018. - 340 c.

3. Власова Е. А., Испаева К.А. Лексические приемы языковой игры (на материале английского языка) // Общетеоретические и частные вопросы современного языкознания. - Чебоксары: Чувашский государственный педагогический университет им. И.Я. Яковлева, 2020. - С. $158-164$.

4. Епанчинцева А.А., Воскресенская Е.Г. Средства создания языковой игры в заголовках англо- и русскоязычных средств массовой информации // Дайджест-2019. - Омск: Омский государственный университет им. Ф. М. Достоевского, 2020. - С. 36-45.

5. Неревяткина Е.А., Белова Н.А. Феномен языковой игры в заголовках современных зарубежных газет // Прорывные научные исследования: проблемы, закономерности, перспективы. - Пенза: «Наука и просвещение», 2020. - С. 150-153.

6. Санников В.3. Русский язык в зеркале языковой игры. - М.: Языки славянской культуры, 2002. -533 с.

7. Свиридонова В.П. Лексика прессы как отражение реалий общественно-политической жизни // Коммуникативные аспекты современной лингвистики и лингводидактики: материалы Международной научной конференции (г. Волгоград, 09 января - 01 апреля 2017 г.). - Волгоград: Издательство ВолГУ, 2017. - C. 27-31.

8. Crystal D., Davy D. Investigating English style. - US: Routledge, 2012. - 278 p.

9. Deborah R., Abel J.S. Importance of Play in the Development of Language and Social Skills // SRM Institute of Science and Technology. - Tamil Nadu, 2018. Pp. 85-96.

10. Horubet M. Language games and playing with language // Language, Discourse, Society. - Oxford: Oxford University Press, 2019. - Pp. 196-201.

() Феопентова Светлана Владимировна (sfeopentova@mail.ru).

Журнал «Современная наука: актуальные проблемы теории и практики»

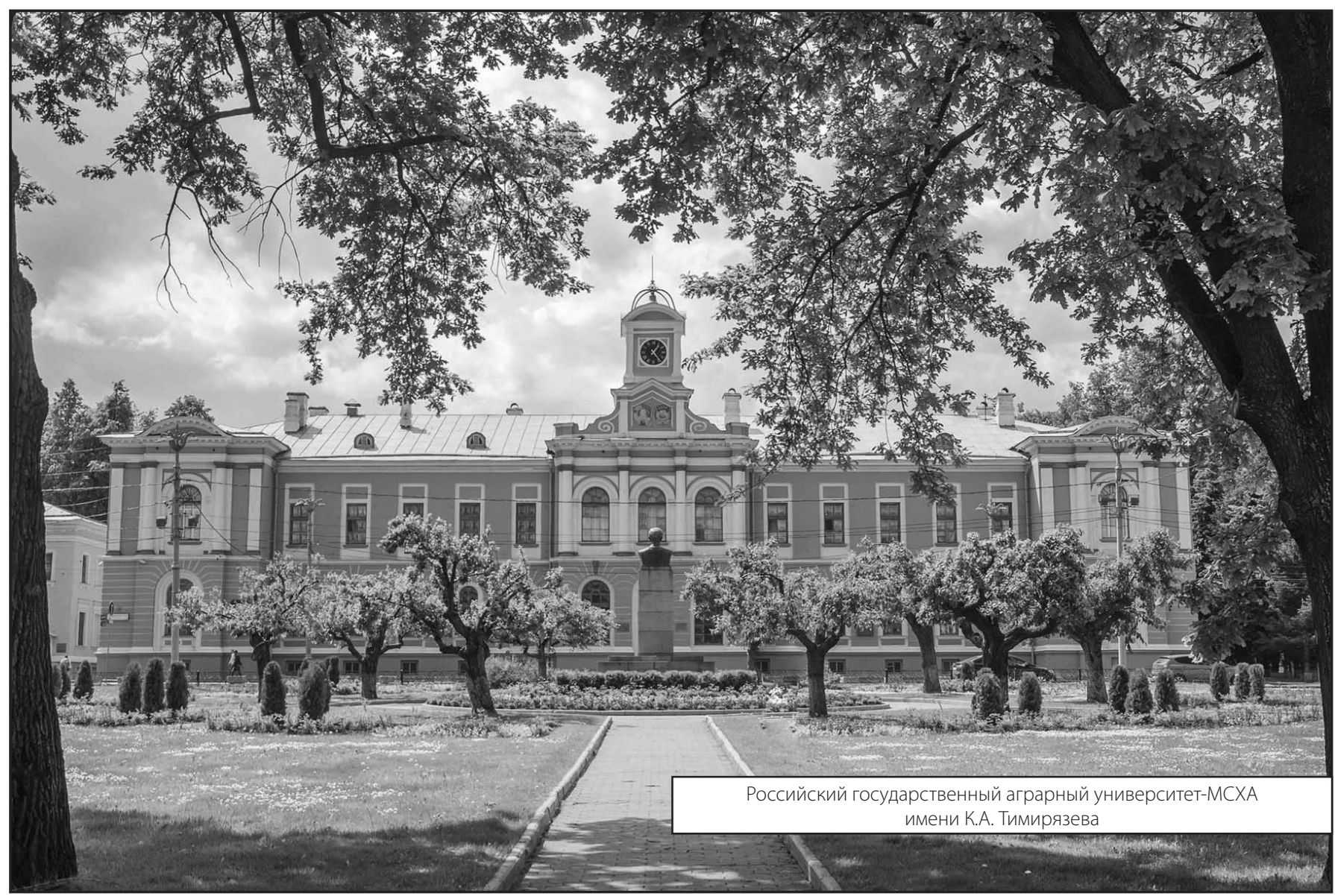

